\title{
Phenoxazinone synthase and antimicrobial activity by a bis(1,3-diamino-2-propanolate) cobalt(III) complex
}

\author{
BISWAJIT CHOWDHURY ${ }^{\mathrm{a}}$, BIPLAB BHOWMIK ${ }^{\mathrm{b}}$, AMRITA SAHU $^{\mathrm{c}}$, MAYANK JOSHI , \\ SUVENDU PAUL ${ }^{\mathrm{d}}$, ANGSHUMAN ROY CHOUDHURY ${ }^{\mathrm{e}}$ and BHASKAR BISWAS ${ }^{\mathrm{a}, *(1)}$

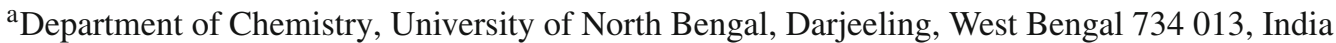 \\ ${ }^{b}$ Department of Zoology, Panchakot Mahavidyalaya, Purulia, West Bengal 723 121, India \\ ${ }^{\mathrm{c}}$ Department of Electrical Engineering, Temple University, Philadelphia 741235, USA \\ ${ }^{\mathrm{d}}$ Department of Chemistry, University of Kalyani, Kalyani, West Bengal 741 235, India \\ e Department of Chemical Sciences, Indian Institute of Science Education and Research Mohali, Mohali, \\ Punjab 140 306, India \\ E-mail: mr.bbiswas@rediffmail.com; icbbiswas@gmail.com
}

MS received 7 July 2018; revised 2 September 2018; accepted 24 September 2018; published online 15 November 2018

\begin{abstract}
In this work, we have synthesised and structurally characterized a mononuclear cobalt(III) complex, $\left[\mathrm{Co}(2-\mathrm{O}-\mathrm{pn})_{2}\right] \mathrm{Cl} \cdot 2 \mathrm{H}_{2} \mathrm{O}(\mathbf{1}),(2-\mathrm{O}-\mathrm{pn}=1,3$-diamino-2-propanolate). From the X-ray structure of the cobalt complex, it is revealed that $\mathrm{Co}$ (III) ion in $\mathbf{1}$ adopts an octahedral geometry and crystallizes in the monoclinic system with $C 2 / c$ space group. The lattice aqua molecule in combination with chloride ion in $\mathbf{1}$ forms a waterchloride cluster, $\left(\mathrm{H}_{2} \mathrm{O}\right)_{2}{ }^{\cdots}(\mathrm{Cl})_{2}$ through strong H-bonding interaction mediated via cobalt(III) complex in a unique binding motif. This cobalt(III) complex has been tested as an effective catalytic system towards the oxidative coupling of 2-aminophenol (2-AP) in the MeCN medium. In situ mass spectral analysis confirms that 2-AP forms an adduct with cobalt ion and the course of catalysis proceeds through catalyst-substrate binding followed by oxidative coupling of 2-AP with iminobenzoquinone. This cobalt(III) catalyst affords exclusively aminophenoxazinone species with a significant turnover number, $k_{\mathrm{cat}}: 6.37 \times 10^{2} \mathrm{~h}^{-1}$ in the MeCN medium. This cobalt(III) complex is able to screen out the growth of some bacteria and fungi species. Quantum chemical calculations employing density functional theory is used to model structural parameters and spectroscopic behaviour. The theoretical findings corroborate well with the experimental results.
\end{abstract}

Keywords. Bio-mimicking Chemistry; Cobalt(III); DFT study; Phenoxazinone synthase activity; X-ray structure.

\section{Introduction}

Cobalt complexes with $(\mathrm{N}, \mathrm{N})$-donor chelators have created a huge appeal to the chemists because of their significant applications in the field of catalysis, drug design, enzymatic bio-functionalities and material science. ${ }^{1-3}$ Among the transition elements, cobalt is a bio-essential element which is found in cobalamin and in some other metalloproteins. ${ }^{4}$ Cobalamin is a necessary part in the formation of myelin that acts as an insulating

\footnotetext{
*For correspondence

BHASKAR BISWAS: On lien from: Department of Chemistry, Surendranath College, Kolkata 700 009, West Bengal, India.
}

layer. It commonly exists around nerves that assist to produce red blood cells including metabolism of fats and carbohydrates, along with protein synthesis. ${ }^{4}$ In general, metal complexes play a pivotal role in the development of antibiotics that is helpful to cure infectious diseases. Metal-based drugs also lead to new antibacterial and antifungal agents which are very effective to resist the growth of microbial infections. ${ }^{5,6}$

On the other hand, catalytic activity on oxidation from 2-aminophenol (2-AP) to 2-amino-3H-phenoxazine-3one (2-APX) by coordination compounds has received considerable attraction for providing important information about bioinorganic reactions and mechanistic aspects in the organic transformation which may open 
a new avenue in molecular science. ${ }^{7-9}$ Actinomycin D, a naturally occurring antineoplastic agent behaves as an inhibitor towards DNA-directed RNA synthesis and is related to questiomycin A which is known as 2-Amino$3 \mathrm{H}$-phenoxazine-3-one. ${ }^{10}$ This species is used clinically for the treatment of certain types of cancer. ${ }^{11}$ It is wellobserved that in the final step of the biosynthesis of actinomycin $\mathrm{D}$, the enzyme phenoxazinone synthase catalyzes the oxidative coupling of 2-aminophenol to the phenoxazinone chromophore. ${ }^{12-14}$ A literature survey indicates that Okamoto et al. ${ }^{15}$ attempted to utilize $\mathrm{Co}$ (III) ion as a blocking agent for 1,3-diamino-2propanol and the stereochemistry of the cobalt complex was determined by ${ }^{13} \mathrm{C}$ NMR. At present, we have introduced the synthesis and structural characterization of a cobalt(III) complex containing a diamine. The lattice aqua molecules and chloride ion in $\mathbf{1}$ interact strongly through $\mathrm{H}$-bonding and help to build a waterchloride cluster, $\left(\mathrm{H}_{2} \mathrm{O}\right)_{2}(\mathrm{Cl})_{2}$ in the crystalline phase. This cobalt(III) complex behaves as a good catalyst with a significant turn over number, $k_{\text {cat }}: 6.37 \times 10^{-2} \mathrm{~h}^{-1}$ in the oxidative coupling of 2-aminophenol in $\mathrm{MeCN}$ medium. Investigation of antimicrobial properties for this cobalt(II) complex reveals that the growth of different bacteria and fungi species is effectively screened by this cobalt(III) complex. Further, detailed theoretical computations on the cobalt(III) complex in vacuum and in methanol are well supported by the experimental observations.

\section{Experimental}

\subsection{Chemicals, solvents and starting materials}

Sufficiently pure 1,3-diamine-2-propanol (Alfa-Aesar, UK), cobalt(II) chloride hexahydrate (E-Merck, India), 2-aminophenol (E-Merck, India) and all other materials were purchased from commercial sources. All other chemicals and solvents are of analytical grade and used as received without further purification.

\subsection{Preparation for $\left[\mathrm{Co}(2-\mathrm{O}-\mathrm{pn})_{2}\right] \mathrm{Cl} 2 \mathrm{H}_{2} \mathrm{O}(\mathbf{1})$}

An aqueous solution of 1,3-diamino-2-propanol ( $0.180 \mathrm{~g}, 2$ $\mathrm{mM}$ in $20 \mathrm{~mL}$ ) is added dropwise to an aqueous solution of $\mathrm{CoCl}_{2} 6 \mathrm{H}_{2} \mathrm{O}(0.237 \mathrm{~g}, 1 \mathrm{mM}$ in $10 \mathrm{~mL})$ and stirred the solution for 30 minutes. The red coloured solution is kept for slow evaporation for 7-10 days and beautiful red coloured single crystal is separated out from the solution,

Yield: $\sim 0.192 \mathrm{~g} \mathrm{(} \sim 81 \%$ based on metal salt). Anal. Calc. for $\mathrm{C}_{6} \mathrm{H}_{22} \mathrm{~N}_{4} \mathrm{O}_{4} \mathrm{ClCo}(\mathbf{1})$ : C, 23.35; H, 7.18; N, 18.15. Found: C, 23.40; H, 7.15; N, 18.21. IR (KBr, cm $\left.{ }^{-1}\right): 3403\left(\nu_{\mathrm{O}-\mathrm{H}}\right)$,

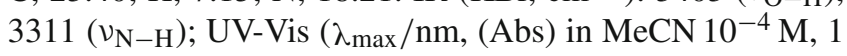

cm optical pathlength): 342 (0.86), 379 (0.68), 475 (0.64); ESI-MS (MeCN): m/z, $273.48\left[\mathrm{Co}(2-\mathrm{O}-\mathrm{pn})_{2} \cdot 2 \mathrm{H}_{2} \mathrm{O}\right]^{+}$(Theoretical m/z, 273.19).

\subsection{Physical measurements}

Elemental analyses (carbon, hydrogen and nitrogen) were performed on a Perkin-Elmer 2400 CHNS/O elemental analyzer. Fourier Transform Infrared (FT IR) spectra (KBr discs, $4000-300 \mathrm{~cm}^{-1}$ ) were recorded using an FTIR-8400S SHIMADZU spectrophotometer in the range $400-3600 \mathrm{~cm}^{-1}$. Steady-state absorption spectral measurements were operated with a JASCO model V-730 UV-Vis spectrophotometer. The ${ }^{1} \mathrm{H}$ nuclear magnetic resonance (NMR) spectra were recorded on a Bruker DPX-500 MHz spectrometer. Electrospray ionization (ESI) mass spectrum was recorded using a Q-tof-micro quadruple mass spectrometer. Molar conductivity measurement was done using a Horiba LAQUA Benchtop DS 70 conductivity meter. A Gouy balance was used to determine the magnetic moments of the powdered samples, employing $\mathrm{Hg}$ (II) tetrathiocyanatocobaltate(II) as a calibrant. Diamagnetic corrections were made from Pascal's constants.

\section{$2.4 X$-ray diffraction study}

Single crystal X-ray diffraction data of the cobalt(III) complex are collected using a Rigaku XtaLABmini (Fixed 2Theta and Distance) diffractometer equipped with Mercury375R (2x2 bin mode) CCD detector. The data are collected with graphite monochromated Mo-K $\alpha$ radiation $(\lambda=0.71073 \AA)$ at 298 $\mathrm{K}$ using $\omega$ scans. The data are reduced using CrysAlisPro 1.171.38.46 (Reference Rigaku Corporation: Tokyo, Japan). The space group determination is done using Olex2. The structure is resolved by direct method and refined by fullmatrix least-squares procedures using the SHELXL-2014/7 ${ }^{16}$ software package through OLEX2 suite. ${ }^{17}$

\subsection{Phenoxazinone Synthase activity by the cobalt(III) complex}

To examine penoxazinone synthase-like activity, $1 \times 10^{-4} \mathrm{M}$ solution of $\mathbf{1}$ in MeCN medium is added to 10 equiv. of 2-aminophenol (2-AP) under aerobic conditions at room temperature. Absorbance vs. wavelength (wavelength scans) of these solutions are recorded at a regular time interval of 8 minutes for 2-AP oxidation in the wavelength range from $300-800 \mathrm{~nm}^{18}$

Kinetic experiments were performed spectrophotometrically with complex 1 and $2-\mathrm{AP}$ in $\mathrm{MeCN}$ at $298 \mathrm{~K}$ for aminophenol oxidation activity. ${ }^{19} 0.04 \mathrm{~mL}$ of the complex solution, with a constant concentration of $1 \times 10^{-4} \mathrm{M}$, is added to $2 \mathrm{~mL}$ of $2-\mathrm{AP}$ of a particular concentration (varying its concentration from $1 \times 10^{-3} \mathrm{M}$ to $1 \times 10^{-2} \mathrm{M}$ ) to achieve the ultimate concentration of the complex as $1 \times 10^{-4} \mathrm{M}$. The conversion of 2-aminophenol to 2-aminophenoxazine-3-one was monitored with time at a wavelength $434 \mathrm{~nm}$ (time scan) 
in $\mathrm{MeCN} .{ }^{20}$ To determine the dependence of rate on substrate concentration, kinetic analyses were performed in triplicate.

Column chromatography technique using neutral alumina as column support and benzene-ethyl acetate as an eluant mixture has been employed to isolate phenoxazinone species in pure form which is obtained through catalytic oxidation of 2-AP. The compound was found in high yield ( $\sim 73 \%$ for 1). ${ }^{1} \mathrm{H}$ NMR spectral analysis was used to identify the species. ${ }^{1} \mathrm{H}$ NMR data for 2-amino-3H-phenoxazine-3-one (APX), $\left(\mathrm{CDCl}_{3}, 400 \mathrm{MHz}\right) \delta_{\mathrm{H}}: 7.62(\mathrm{~m}, 1 \mathrm{H}), 7.44(\mathrm{~m}, 3 \mathrm{H})$, $6.47(\mathrm{~s}, 1 \mathrm{H}), 6.39(\mathrm{~s}, 1 \mathrm{H}), 6.28(\mathrm{~s}, 1 \mathrm{H})$. The identification of this phenoxazinone product is further consolidated in ESI-Ms spectrometry from the appearance of a base peak at m/z 213 .

\subsection{Detection of the presence of hydrogen peroxide in the catalytic oxidation of 2-aminophenol}

To ensure the active participation of molecular oxygen in the course of catalysis, the formation of hydrogen peroxide was checked. ${ }^{2 b},{ }^{19}$ It is well-known that molecular oxygen in oxidative catalytic reactions transforms into hydrogen peroxide or water as a byproduct. In this course of the oxidative catalytic reaction, the solution is acidified with $\mathrm{H}_{2} \mathrm{SO}_{4}$ to become $\mathrm{pH} 2$. After a certain time, an equal volume of water is added to stop further oxidation. The phenoxazinone species are extracted three times with dichloromethane. $1 \mathrm{~mL}$ of $10 \%$ solution of KI and three drops of a $3 \%$ solution of ammonium molybdate are added to the aqueous layer. The formation of $\mathrm{I}_{3}^{-}$could be monitored spectrophotometrically because of the development of the characteristic $\mathrm{I}_{3}^{-}$band $\left(\lambda_{\max }=353 \mathrm{~nm}\right)$.

\subsection{In vitro antimicrobial activity study}

Some of the microbial (bacterial and fungal) strains, Escherichia coli $8739^{T M}$, Staphylococcus aureus $6538^{T M}$, Salmonella typhi $14028^{T M}$, Proteus vulgaris $8427^{T M}$, Klebsiella pneumoniae $700721^{T M}$ and Cryptococcus neoformans MYA-565 ${ }^{T M}$, Fusarium oxysporum and Aspergillus niger $16404^{T M}$ were sourced from ATCC. This Co(III) complex was tested against these bacterial and fungal species cultured on dextrose agar medium by the well diffusion method. ${ }^{21}$ The growth of bacterial organisms was observed on muller hinton agar while the effect of cobalt complex on fungal species was studied on sabouraud dextrose agar in petri plates. The pathogens were swabbed uniformly onto the individual plates using sterile cotton swabs. Different concentration $(10 \mu \mathrm{g}, 50 \mu \mathrm{g}$ and $100 \mu \mathrm{g})$ of the test sample was poured onto each well on all plates. After incubation at $37^{\circ} \mathrm{C}$ for $24 \mathrm{~h}$ for bacteria and $28^{\circ} \mathrm{C}$ for $72 \mathrm{~h}$ for fungi, the different levels of the zone of inhibition were measured.

\subsection{Computational details}

Ignoring symmetrical restrictions, the quantum chemical computations were performed with Gaussian 09W programme suite. ${ }^{22}$ For all the atoms, B3LYP theoretical model and widely used $6-311 \mathrm{G}$ basis set ${ }^{23,24}$ were compiled with density functional theory (DFT) for the ground state and time-dependent density functional theory (TD-DFT) for excited state computations. Firstly, we optimized the mononuclear cobalt(III) complex, $\mathbf{1}$ in a vacuum and then in acetonitrile $(\varepsilon=35.688)$ employing integral equation formalism polarizable continuum model (IEFPCM). ${ }^{25-28}$ Thereafter, the stability of all the complexes were confirmed through theoretical IR frequency calculations. The images of molecular structure and frontier molecular orbitals (FMOs) were extracted from checkpoint files.

\section{Results and Discussion}

\subsection{Synthesis, spectroscopic behaviour and solution properties of cobalt(III) complex (1)}

Bis(1,3-diamino-2-propanolate)cobalt(III) chloride dihydrate is prepared (Scheme 1) in the form of single crystal by addition of hydrated cobalt(II) chloride with diamine chelator in an aqueous methanolic medium under stirring condition. The structural formulation is defined through different analytical techniques. The geometry of the cobalt(III) complex (1) is determined and confirmed by single crystal X-ray diffraction study.

The IR spectrum for this cobalt(III) complex (Figure S1, Supplementary Information) displays a broad peak at $\sim 3403 \mathrm{~cm}^{-1}$ which is assignable to the $\mathrm{O}-\mathrm{H}$ stretching frequency for the lattice aqua molecule. Another, strong peaks at $\sim 3311 \mathrm{~cm}^{-1}$ corresponds to the N-H frequency of diimine ligands. ${ }^{29}$ Room temperature magnetic measurement confirms that cobalt(III) ion in 1 exists in low spin conformation. The magnetic moment $\left(\mu_{\text {eff }}\right)$ is found as $\sim 0.01 \mathrm{BM}$ and consolidates the diamagnetic nature of cobalt centre in the solid state. Room temperature EPR spectrum of $\mathrm{Co}$ (III) compound in $\mathrm{MeCN}$ remains silent $(\mathrm{S}=0$ in ground state) that authenticates the low spin conformation of $\mathrm{Co}$ (III) species in $\mathbf{1}$.

The UV-Vis spectrum of $\mathbf{1}$ for $1 \times 10^{-4} \mathrm{M}$ in $\mathrm{MeCN}$ solution shows the main characteristic electronic transitions at 342, 379 and $475 \mathrm{~nm}$. The high energy band at $342 \mathrm{~nm}$ is assignable to the ligand to metal charge transfer (LMCT). Another two important characteristics of electronic transitions at 379 and $475 \mathrm{~nm}$ arise

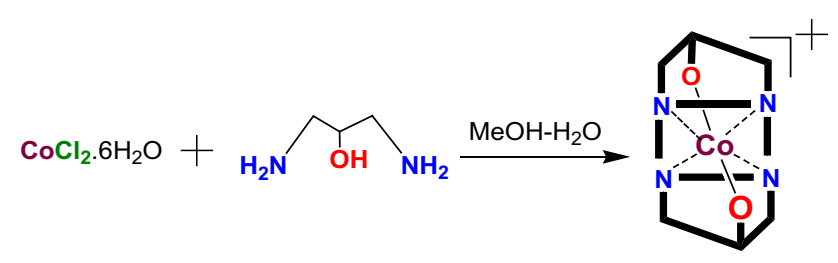

Scheme 1. Preparative procedure of Co(III) complex (1). 
for the existence of low spin cobalt(III) species of octahedral geometry in solution (Figure S2, Supplementary Information). ${ }^{30}$ Furthermore, these electronic bands at $379 \& 475 \mathrm{~nm}$ correspond to ${ }_{1} \mathrm{~A}^{1 \mathrm{~g}} \rightarrow{ }_{1} \mathrm{~T}^{2 \mathrm{~g}}$ and ${ }_{1} \mathrm{~A}^{\lg } \rightarrow{ }_{1} \mathrm{~T}^{\lg }$ transitions respectively. ${ }^{30}$ The structural solidity in $\mathrm{MeCN}$ for the cobalt(III) complex has been further confirmed by ESI mass spectrum. ESI mass spectral analysis of $\mathbf{1}$ in $\mathrm{MeCN}$ displays the primary zone of coordination for this cobalt(III) complex as the most stable species in solution and exhibits the characteristic peak at $\mathrm{m} / \mathrm{z} 273.43$ corresponds to $\left[\mathrm{Co}(2-\mathrm{O}-\mathrm{pn})_{2} \cdot 2 \mathrm{H}_{2} \mathrm{O}\right]^{+}$ionic species in solution (Figure S3, Supplementary Information). The optical bands of the cobalt(III) complex in MeCN solution remain unchanged over a period of $72 \mathrm{~h}$. This observation suggests that this mononuclear cobalt(III) is stable in its original form in solution. We have also recorded an EPR spectrum of $\mathbf{1}$ in the $\mathrm{MeCN}$ medium at room temperature. The nature of EPR plot is found as silent and justifies its low spin conformation of cobalt(III) ion in the MeCN medium. The EPR result suggests the diamagnetic nature of the cobalt(III) complex. To investigate the electrolytic nature of the complex in $1.0 \times 10^{-3} \mathrm{M} \mathrm{MeCN}$ solution, we have also recorded molar conductance value at room temperature. The value of molar conductivity is found as $95 \mu \mathrm{S} / \mathrm{cm}$ which suggests about 1:1 electrolytic behaviour in solution.

\subsection{Depiction of X-ray structure}

Single crystal X-ray diffraction study of the cobalt(III) complex defines the coordination linkages of the primary and secondary zone of coordination around cobalt (III) centre. The ORTEP diagram of the cobalt(III) complex is shown in Figure 1. The molecular structure of 1 reveals that cobalt(III) complex crystallizes in a monoclinic system with $C 2 / c$ space group. The cobalt(III) ion in the primary zone of coordination satisfies by two tridentate 1,3-diamino-2-propanol ligands in an octahedral geometry. Very interestingly, we are able to isolate the cobalt complex in trans-form. This form of complex contains higher symmetry elements like the plane of symmetry and centre of inversion. Furthermore, the coordination motif of this tri-dentate chelator doesn't allow to produce $c i s$-form. The existence of trans-form is also attested from symmetry perspective.

Though the free amine has an aliphatic-OH group, in reaction with cobalt(III) ion, the ligand acts as a monoanionic system and interestingly, the trans form is isolated as red crystals from the solution. The residual cationic charge of the bis-chelate cobalt(III) complex is neutralized by counter anionic chloride ion in the secondary zone of coordination. The $\mathrm{Co} 1-\mathrm{O} / \mathrm{N}$ bond

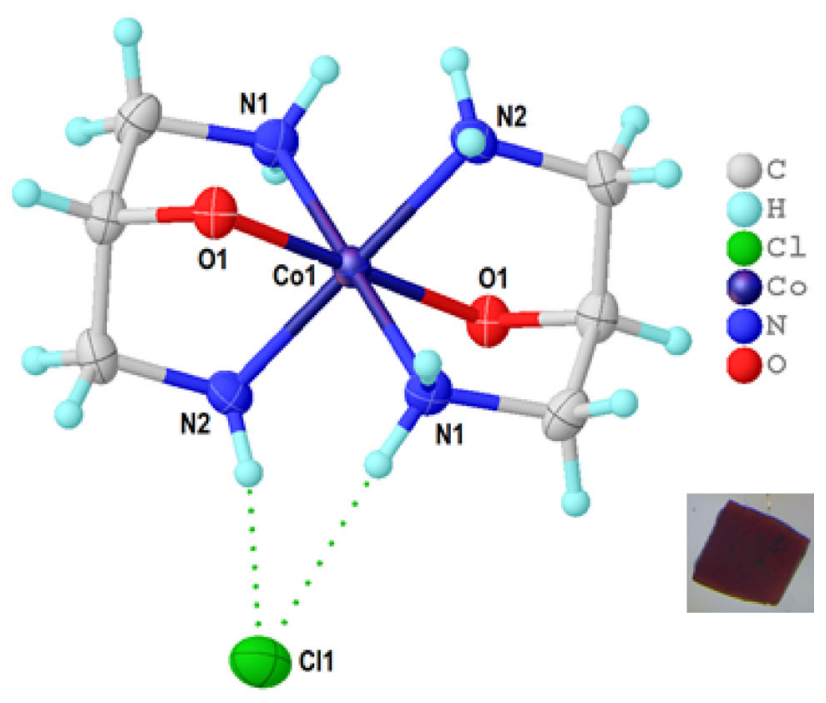

Figure 1. An ORTEP diagram of cobalt(III) complex with $30 \%$ ellipsoid probability. Inset: Microscopic image of the single crystal for red coloured cobalt(III) complex.

lengths are found in the range from 1.90 to $1.96 \AA$. A comparison on crystallographic bond distances among this $\mathrm{Co}$ (III) complex with previously reported mononuclear cobalt(III) complexes ${ }^{30 a, b, c, 40}$ accounts that average $\mathrm{Co}-\mathrm{N}$ distances of $\mathrm{Co}$ (III) compounds with low spin confirmation lie 1.90 to $1.94 \AA$ and helps to predict the existence of $\mathrm{Co}$ (III) species in low spin conformation in crystalline state. The single crystal X-ray diffraction refinement parameters for $\mathbf{1}$ are presented in Table 1 . Important bond lengths and angles for $\mathbf{1}$ are also summarized in Table 2.

\subsection{Investigation of crystalline architectures including water-chloride cluster}

In order to view the involvement of weak forces in the growth of crystalline architectures in the solid state for this cobalt complex, it is found that lattice water molecules and chloride anions play a significant role through the $\mathrm{H}$-bonded network. It is seen that two chloride ions in association with three lattice water molecules form a water-chloride cluster that extends along $b$ axis through another set of H-bonded interactions with metal-ligand backbone and leads to a novel mode of association. As a result, a 3D crystalline architecture is constructed in the solid state (Figure 2). The intermolecular hydrogen bonding association plays a pivotal role in forming a water-chloride cluster along $b$-axis among the lattice aqua molecules and counter anionic chloride ions $[(\mathrm{O} 2-\mathrm{H} 2 \mathrm{c} \cdots \mathrm{Cl} 1,2.39 ; \mathrm{O} 2-\mathrm{H} 2 \mathrm{~d}$. . C C11, 2.53; C3-H3b ‥ Cl1, 2.82; N2-H2b . . Cl1, 2.39; N1-H1a ‥ O2, 2.23 Å; Figure 2, Table S1, Supplementary Information]. To the best of our knowledge, 
Table 1. Crystallographic refinement parameters of $\left[\mathrm{Co}(2-\mathrm{O}-\mathrm{pn})_{2}\right] \mathrm{Cl} \cdot 2 \mathrm{H}_{2} \mathrm{O}(\mathbf{1})$.

\begin{tabular}{lc}
\hline Crystal parameters & $\mathbf{1}$ \\
\hline Empirical formula & $\mathrm{C}_{6} \mathrm{H}_{22} \mathrm{~N}_{4} \mathrm{O}_{4} \mathrm{ClCo}$ \\
Formula weight & 308.43 \\
Temperature & $298 \mathrm{~K}$ \\
Wavelength & $0.71075 \AA$ \\
Crystal system & Monoclinic \\
Space group & $C 2 / c$ \\
Unit cell dimensions & $\mathrm{c}=15.9657(3) \AA, \alpha=90^{\circ} ; \mathrm{b}=8.0882(3) \AA$ \\
& $B=105.50(5)^{\circ} ; \mathrm{c}=10.7397(5) \AA, \gamma=90^{\circ}$ \\
Volume & $1336.42(11) \AA^{3}$ \\
Z & 4 \\
Density (calculated) & $1.710 \mathrm{~g} / \mathrm{cm}^{3}$ \\
Absorption coefficient & $1.693 \mathrm{~mm}^{-1}$ \\
Reflections collected & 8937 \\
Independent reflections & 1959 \\
R(int) & 0.021 \\
Goodness-of-fit on F2 & 1.13 \\
R indices (all data) & $\mathrm{R} 1=0.0353, \mathrm{wR}^{3}=0.0958$ \\
Largest diff. peak and hole & 1.34 and $-0.62 \mathrm{e} . \AA^{-3}$ \\
\hline
\end{tabular}

Table 2. Selected bond lengths $(\AA)$ and bond angles $\left({ }^{\circ}\right)$ for $\left[\mathrm{Co}(2-\mathrm{O}-\mathrm{pn})_{2}\right] \mathrm{Cl} \cdot 2 \mathrm{H}_{2} \mathrm{O}(\mathbf{1})$ from the XRD structure (values within the parenthesis denote the corresponding data obtained from DFT study).

\begin{tabular}{lccccc}
$\begin{array}{l}\text { Bond lengths }(\AA) \\
\text { Co1-O1 }\end{array}$ & $\begin{array}{l}\text { 1.9007 (1.886) } \\
\text { Co1-N1 }\end{array}$ & Co1-N2 & $1.9637(1.992)$ & & \\
Bond angles $\left({ }^{\circ}\right)$ & & & & \\
O1-Co1-N1 & $86.67(85.5)$ & O1-Co1-O1* & $180.0(180.0)$ & O1-Co1-N2* & $95.91(94.1)$ \\
O1-Co1-N2 & $84.09(85.5)$ & O1-Co1-N1* & $93.33(94.7)$ & N1-Co1-N2 & $85.75(85.7)$ \\
O1*-Co1-N1 & $93.33(94.5)$ & N1-Co1-N1* & $180.0(180.0)$ & N1-Co1-N2* & $94.25(94.2)$ \\
O1*-Co1-N2 & $95.91(94.2)$ & N2-Co1-N2* & $180.0(179.9)$ & O1*-Co1-N1* & $86.67(85.5$ \\
O1*-Co1-N2* & $84.09(85.8)$ & N1*-Co1-N2* & $85.75(85.7)$ & & \\
\hline
\end{tabular}

this mode of binding between solvent molecules and counter-anionic chloride will be a novel one that wasn't previously observed.

\subsection{Theoretical modelling of the structure and frontier molecular orbitals}

The structural integrity of the mononuclear $\mathrm{Co}$ (III) complex is studied by computational modelling using DFT calculation. The calculated structure of $\mathbf{1}$ in a vacuum (Figure 3 ) in accordance with the X-ray structure. In addition, the bond lengths and bond angles are in good agreement with the experimental values (Table 2). The gas phase structure also defines the similar degree of denticity (tridentate) for 2-hydroxy1,3-diaminopropane ligand towards cobalt ion and consolidates the formation of bis-chelate structure in trans conformation. The cobalt ion is also octahedrally surrounded by four nitrogen atoms and two oxygen ion like the mapping of coordination in single crystal X-ray structure.

We have also performed excited state calculation, which is widely used to define the optical properties of the metal complex in $\mathrm{MeCN}$. The energy gap between $\mathrm{HOMO} \rightarrow$ LUMO and HOMO $-1 \rightarrow$ LUMO +1 (Figure 4 ) portrayed a clear view regarding the electronic activity of $\mathbf{1}$ in solution. It is well-established that low HOMO-LUMO energy gap provides higher chemical activity and lower thermal stability of a molecule. The experimental and simulated UV-Vis wavelengths along with the major contributing orbitals and oscillator strengths for $\mathbf{1}$ are reported in Table S4, Supplementary Information.

3.5 Phenoxazinone synthase mimicking the activity of the cobalt(III) complex (1)

The 2-aminophenol oxidation activity by the cobalt(III) complex (1) is examined using a convenient substrate 


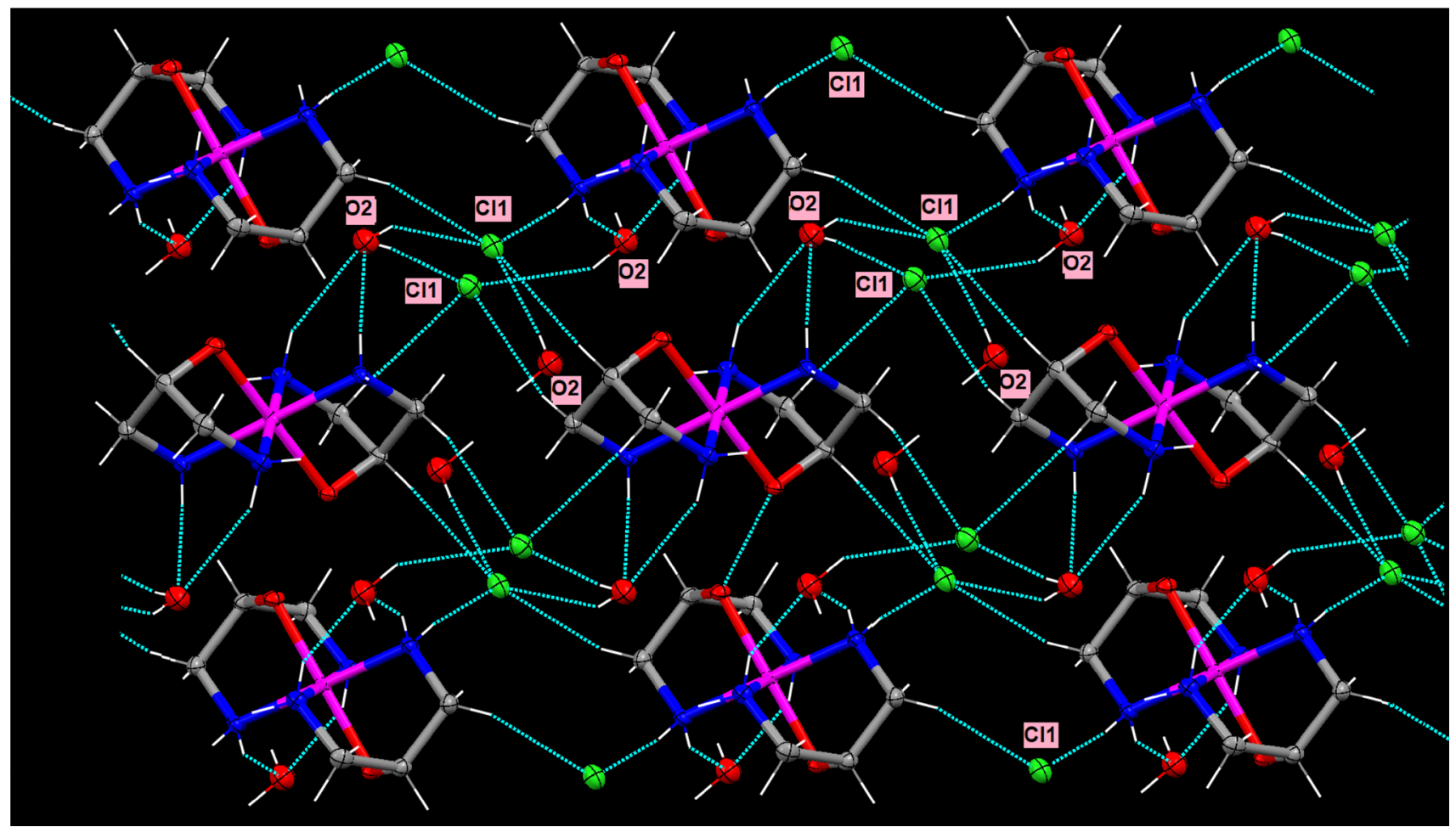

Figure 2. Formation of $\left[(\mathrm{Cl}) \cdots\left(\mathrm{H}_{2} \mathrm{O}\right)_{3}\right] \cdots\left[\mathrm{Co}(2-\mathrm{O}-\mathrm{pn})_{2}\right] \mathrm{Cl} \cdot \mathrm{H}_{2} \mathrm{O}$ crystalline architectures in $\mathbf{1}$ [Red, green and blue colours in ORTEP indicate $\mathrm{O}, \mathrm{Cl}$ and $\mathrm{N}$ atoms, respectively].

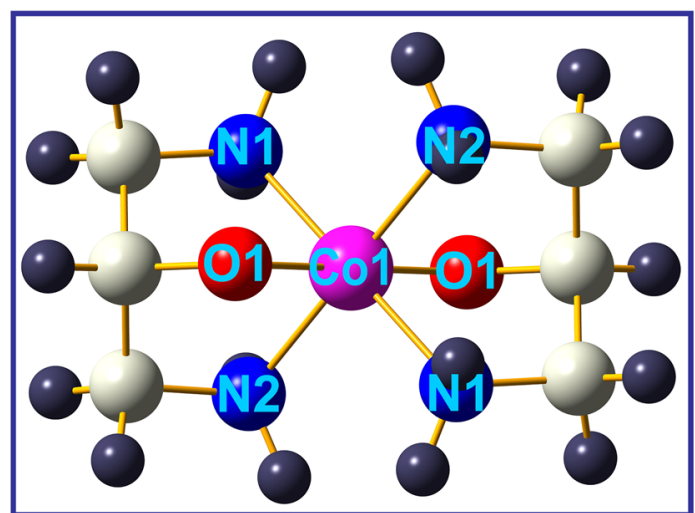

Figure 3. Optimized structure of $\mathbf{1}$ in vacuum using DFT/B3LYP/6-311G theory.

2-aminophenol (2-AP) under the aerobic condition in $\mathrm{MeCN}$ at room temperature $\left(25^{\circ} \mathrm{C}\right)$ (Scheme 2$)$.

To study the catalytic oxidation of 2-aminophenol, $1 \times 10^{-4} \mathrm{M}$ solution of $\mathrm{Co}(\mathrm{III})$ complex is added to a $1 \times 10^{-3} \mathrm{M}$ solution of 2 -AP in MeCN medium. The course of catalysis is monitored using UV-Vis spectrophotometer. The time-dependent scan is recorded at a time interval of $8 \mathrm{~min}$ for 2 h. 2-AP in MeCN solution displays a single band at $267 \mathrm{~nm}$ which is an indication for its pure form in solution. It is observed during the spectrophotometric titration, upon addition

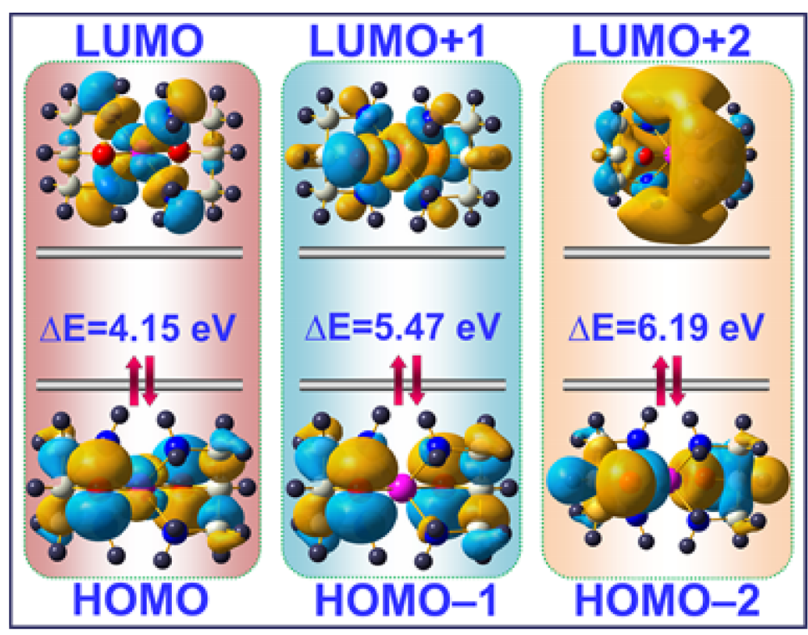

Figure 4. Frontier molecular orbitals of $\mathbf{1}$ along with the corresponding transition energy values calculated using TD-DFT/B3LYP/6-311G theoretical model and IEFPCM/acetonitrile solvent system.

of cobalt complex to 2-AP in $\mathrm{MeCN}$, absorbance value for 2-AP at $267 \mathrm{~nm}^{31}$ is gradually decreased with the progress of time (Figure S4, Supplementary Information). Simultaneously, a new band at $434 \mathrm{~nm}$ with incremental absorbance was observed (Figure 5, Figure S4, Supplementary Information). The appearance of the new optical band at $434 \mathrm{~nm}$ upon addition of cobalt 


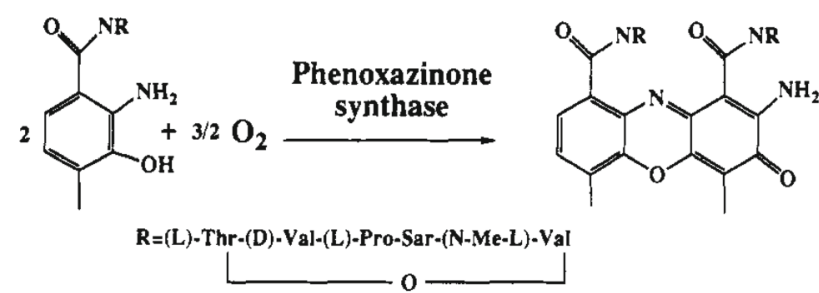

Scheme 2. Catalytic oxidation of 2-aminophenol by phenoxazinone synthase.

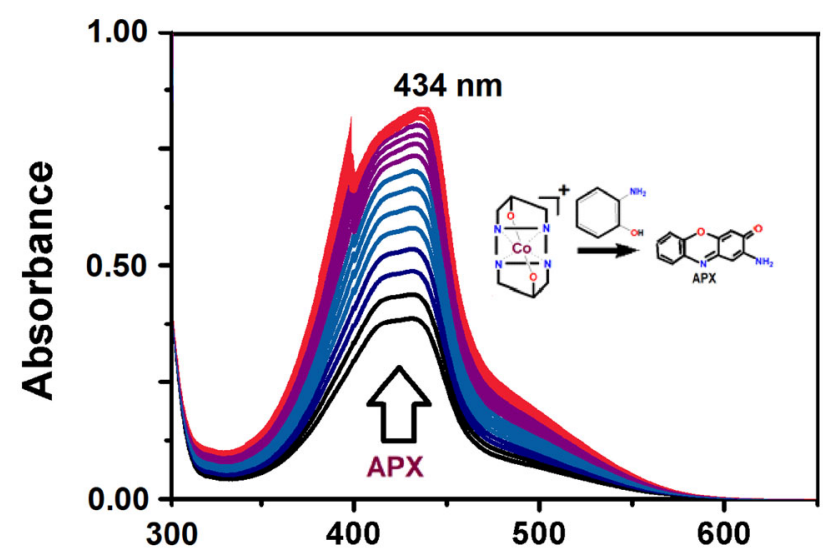

Figure 5. Increase of absorbance for the production of aminophenoxazinone at $434 \mathrm{~nm}$ upon catalytic addition of 1 to 10 equivalents of 2-AP in MeCN. The spectra were recorded after every $8 \mathrm{~min}$ at $298 \mathrm{~K}$.

complex is a definite sign for the catalytic production of aminophenoxazinone species in solution. ${ }^{32-34}$ The controlled experiment was also carried out for phenoxazinone synthase activity using 2-AP in MeCN solvent under the aerobic atmosphere at room temperature. We have also performed the controlled experiments in presence of 1,3-diamino-2-propanol to 2-AP under identical reaction conditions (Figure S5, Supplementary Information). However, no significant growth of phenoxazinone species was observed up to $2 \mathrm{~h}$. Close inspection of the spectrophotometric titration on aminophenol oxidation, it is suggested that the titration curves get saturated after $2 \mathrm{~h}$ of catalysis by the mononuclear cobalt(III) complex.

The details of kinetic investigations for the catalytic oxidation of 2-AP were performed to realize the efficacy for this cobalt(III) catalyst. The method of initial rates was followed to unveil the nature of kinetic for this catalytic oxidation of 2-AP. The growth of phenoxazinone chromophore was monitored at $434 \mathrm{~nm}$ as a function of time (Figure S6, Supplementary Information). ${ }^{35,36}$ The plot of rate constants versus concentration of the substrate displayed the saturation kinetics. The values of kinetics parameters were determined from the Michaelis-Menten approach of enzymatic kinetics 1 and presented in Table 3.
With an aim to check the level of phenoxazinone synthase reactivity between our cobalt complex and few other reported cobalt(III) complexes we have made a comparison in Table 3 . The catalytic efficiency for $\mathbf{1}$, $k_{\text {cat }} / \mathrm{K}_{M}=2.02 \times 10^{5}$ towards catalytic aminophenol oxidation was also found high.

To view the insights of the mechanistic route, we studied important scientific literature about catalytic phenoxazinone activity by the metal complexes. Previously, Chaudhury and co-workers ${ }^{37}$ modeled a tetracopper complex for the mimicking the bio-functionalities of phenoxazinone synthase enzyme. They proposed an 'on-off' mechanism of radicals in association with the electronic participation of the metal centers in favour of 6e oxidative coupling of the substrate in the course of catalysis containing enzyme phenoxazinone synthase. On the other hand, Begley et al., ${ }^{37}$ recommended the synthesis of 2-aminophenoxazinone through a sequence of three consecutive $2 \mathrm{e}$ substrate oxidations. The tautomerization reactions were the controlling unit in the regeneration of the 2-Ap during this course of the catalytic oxidation reaction.

We have recorded in situ electron spray ionization (ESI) mass spectrum of the reaction mixture in $\mathrm{MeCN}$ medium to gain important information to propose the catalytic route by cobalt(III) complex in the oxidative coupling of 2-AP to phenoxazinone species. ESI-MS provides very valuable information about the generation of reactive species and product during the course of catalysis. The ESI mass spectral analysis of the reaction mixture (Figure S7, Supplementary Information) for $\mathbf{1}$ in $\mathrm{MeCN}$ medium exhibited the characteristics peaks at $\mathrm{m} / \mathrm{z} 214.56$ and 346.28 with isotope distribution patterns. This ESI mass spectral results strongly recommended the corroboration of [(2-amino- $3 \mathrm{H}$ - phenoxazine-3-ones $\left.)+\mathrm{H}^{+}\right]$and $\left[\left[\mathrm{Co}(2-\mathrm{O}-\mathrm{pn})_{2}(2-\mathrm{AP})\right]+\mathrm{H}^{+}\right]$at $\mathrm{m} / \mathrm{z} 214.56$ and 346.28 respectively. Furthermore, ${ }^{1} \mathrm{H}$ NMR of the cobalt(III) complex in presence of 2-AP in 1:10 ratio in $\mathrm{CDCl}_{3}$ was recorded (Figure S8, Supplementary Information). The reaction mixture was kept in an open atmosphere for $10 \mathrm{~min}$ to allow the participation of molecular oxygen under slow stirring condition. The appearance of proton signals corresponding to aromatic protons (6.0 to $7.8 \mathrm{ppm}$ ) of 2-AP and oxidative coupling product, APX respectively attested the generation of substrate-catalyst adduct during the catalytic oxidation of 2-AP. The raising proton signals in the range 2 to $4.2 \mathrm{ppm}$, however, justified the presence of aliphatic- $\mathrm{H}$ and $-\mathrm{NH}_{2}$ of ligand backbone (Figure S8, Supplementary Information).

ESI-MS spectral analysis made a recommendation that the catalytic oxidations are carried out by these cobalt(III) complexes through catalyst-substrate 
Table 3. Kinetic parameters for the catalytic oxidation of 2-AP by $\mathbf{1}$ in $\mathrm{MeCN}$ at $25^{\circ} \mathrm{C}$.

\begin{tabular}{lcccl}
\hline Complex & $\mathrm{V}_{\max }\left(\mathrm{M} \mathrm{s}^{-1}\right)$ & $\mathrm{K}_{\mathrm{m}}(\mathrm{M})$ & $\mathrm{k}_{\mathrm{cat}}\left(\mathrm{h}^{-1}\right)$ & \multicolumn{1}{c}{ Ref } \\
\hline $1^{*}$ & $1.77 \times 10^{-5}$ & $3.16 \times 10^{-3}$ & $6.37 \times 10^{2}$ & This work \\
1 & $7.87 \times 10^{-4}$ & $4.31 \times 10^{-4}$ & $2.83 \times 10^{4}$ & 38 \\
1 & $4.62 \times 10^{-6}$ & $0.67 \times 10^{-4}$ & $4.62 \times 10^{2}$ & 39 \\
2 & $1.74 \times 10^{-5}$ & $3.23 \times 10^{-4}$ & $1.74 \times 10^{-1}$ & 39 \\
\hline
\end{tabular}

Std. Error for $1, \mathrm{~V}_{\max }\left(\mathrm{M} \mathrm{s}^{-1}\right)=8.93 \times 10^{-7}$; Std. Error for $\mathrm{K}_{\mathrm{m}}(\mathrm{M})=2.74 \times 10^{-4}$.

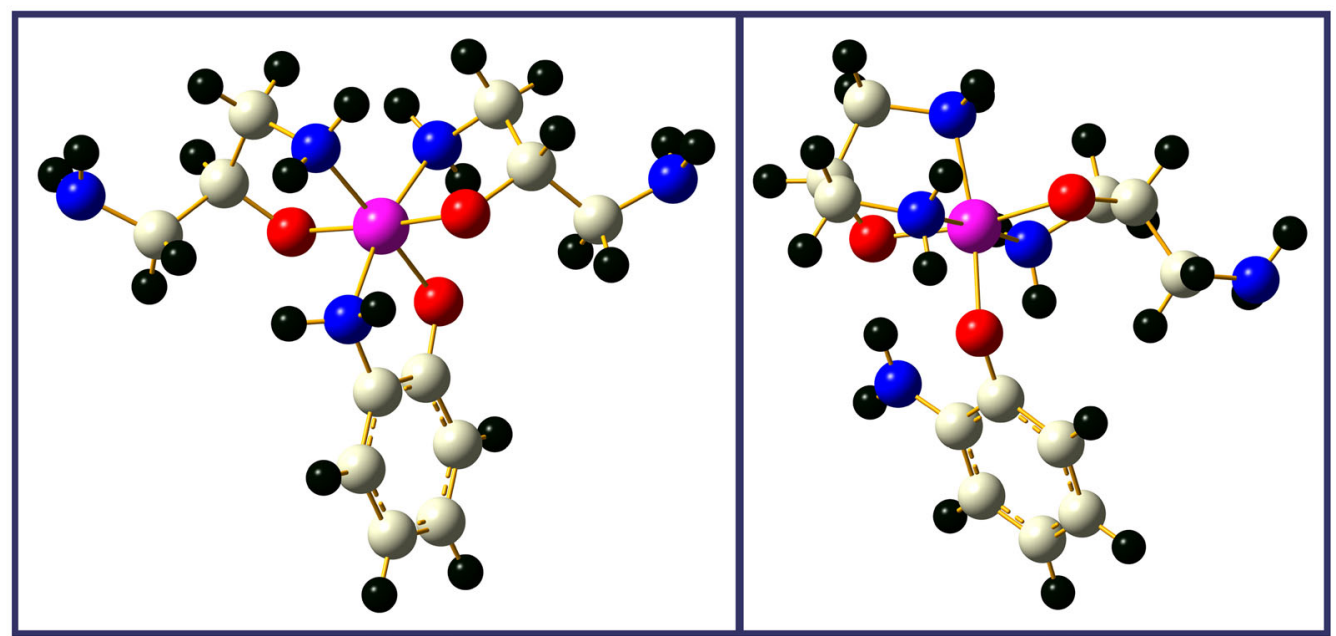

Scheme 3. Optimized structures of the 2-AP with Co(III) complex in chelating mode (left, A form) \& monodentate mode (Right, B-form) of binding for 2-AP.

intermediate in the course of catalytic oxidation. Now, 2-AP can behave as a chelating ligand as well as a monodentate donor system. To explore the mode of binding of the substrate, 2-AP towards catalyst, we made an investigation through computational modeling on substrate-catalyst adducts (Scheme 3). Energy calculations in solvent phase on catalyst-substrate adducts, it was observed that 2-AP adduct with $\mathrm{Co}$ (III) centre through chelating mode (A) was more energy efficient than 2-AP adduct with $\mathrm{Co}(\mathrm{III})$ ion in monodentate motif (B).

Furthermore, the involvement of molecular oxygen as a participant in the course of catalysis was examined. Hydrogen peroxide was detected and extracted as a byproduct in the course of phenoxazinone synthase activity (Figure S9, Supplementary Information). The cobalt(III) complex in this oxidative catalysis couldn't be regenerated since the structural rearrangement at Co(III) centre in $\mathbf{1}$ did not allow to return back into its original form. Thus, we were unable to recycle the $\mathrm{Co}$ (III) catalyst in its original form during this oxidative catalysis of 2-AP. Now, on the basis of experimental and theoretical observations, it can be proposed (Scheme 4) that the course of catalytic oxidation of 2-AP primarily proceeds through the formation of substrate-catalyst adduct followed by generation of iminobenzoquinone. The iminobenzoquinone further couples with another molecule of 2-AP to produce aminophenoxazinone species in solution.

\subsection{Bio-Assay Investigations}

To evaluate the antimicrobial property of the cobalt(III) complex, we applied the Co(III) complex towards some test organisms. $100 \mu \mathrm{L}$ of each of the microbial suspension was spread onto agar plates which correspond to the broth in which they were maintained. Isolated colonies for each of the organisms those might be playing a pathogenic role should be selected from primary agar plates and tested for susceptibility by well diffusion method. The screened antimicrobial activity by the cobalt(III) complex is displayed in Figure S10 (Supplementary Information) and the results are presented in Tables S2 and S3, Supplementary Information. 


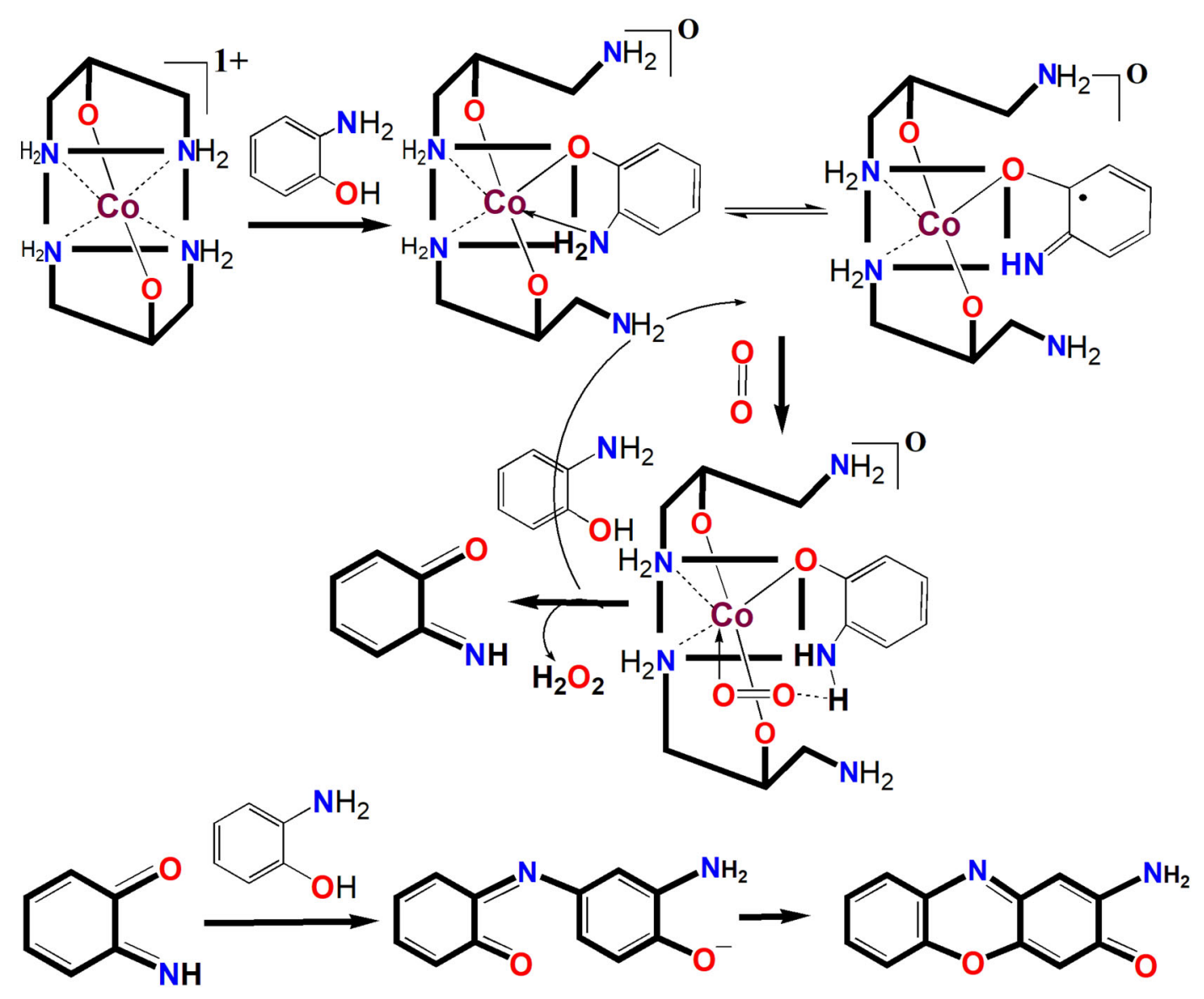

Scheme 4. Proposed mechanistic pathway for 2-AP oxidation activity by $\mathbf{1}$.

The $\left[\mathrm{Co}(2-\mathrm{O}-\mathrm{pn})_{2}\right] \mathrm{Cl}^{2} 2 \mathrm{H}_{2} \mathrm{O}$ (1) complex showed the maximum antimicrobial activity against the Staphylococcus aureus, Salmonella typhi, Fusarium oxysporum. This cobalt(III) complex exhibited average or minimum antimicrobial activity against Escherichia coli, Klebsiella pneumonia, Proteus vulgaris, Cryptococcus neoformans, Aspergillus niger microorganisms.

The enhanced activity of the complex can be explained on the basis of mechanistic aspects of Tweedy's Chelation theory. ${ }^{40}$ It is commonly observed that lipid and polysaccharides which are important constituents of cell walls and membranes show a preference for metal ion interaction. In addition to this, the cell wall also contains amino phosphates, carbonyl and cysteinyl ligands, which maintain the integrity of the membrane acting as a diffusion barrier and also provides a suitable site for bonding. In our case, metal-ligand coordination reduces the polarity of the metal ion significantly which makes this mononuclear Co(III) complex least-polar. The metal-chelate is probably adsorbed on the surface of the cell wall of microorganisms through the interactions with the preferential active sites and disturbs the respiration process of the cell. As a result, synthesis of the proteins is blocked that restricts further growth of the organisms. So, the Co(III) complex behaves as the growth-inhibitor for the microorganism in an effective way.

\section{Conclusions}

Herein, we synthesized a mononuclear cobalt(III) complex, $\left[\mathrm{Co}(2-\mathrm{O}-\mathrm{pn})_{2}\right] \mathrm{Cl} \cdot 2 \mathrm{H}_{2} \mathrm{O}$ (1) (2-O-pn = 1,3-diamino2-propanolate) and structurally characterized through different analytical techniques. We were able to isolate the compound as red coloured crystals in single phase. $\mathrm{X}$-ray structural analysis revealed that $\mathbf{1}$ crystallized in the monoclinic system with $C 2 / c$ space group. The lattice aqua molecules in combination with chloride ions in 1 presents a novel mode of supramolecular association and forms a water-chloride cluster, $\left(\mathrm{H}_{2} \mathrm{O}\right)_{2}(\mathrm{Cl})_{2}$ through strong $\mathrm{H}$-bonding interaction mediated via cobalt(III) complex. Theoretical modeling by Density Functional Theory (DFT) was employed to obtain structural \& spectroscopic parameters. The theoretical findings were well-corroborated with the experimental results. This cobalt(III) complex was evaluated as an effective catalytic system towards the oxidative coupling of 2-aminophenol (2-AP) in the MeCN medium. In situ 
mass spectral analysis confirmed that 2-AP forms an adduct with cobalt ion and the course of catalysis proceeded through catalyst-substrate binding followed by oxidative coupling of 2-AP with iminobenzoquinone. This cobalt(III) catalyst afforded exclusively aminophenoxazinone species with a significant turn over number, $k_{\text {cat }}: 6.37 \times 10^{2} \mathrm{~h}^{-1}$ in the MeCN medium. This cobalt(III) complex was also able to screen the growth of some bacteria and fungi species.

\section{Supplementary Information (SI)}

Crystallographic data are available free of charge from The Director, CCDC, 12 Union Road, Cambridge, CB2 1EZ, UK (fax: +44-1223-336033; Email: deposit@ccdc. cam.ac.uk or www: http://www.ccdc.cam.ac.uk) upon request, quoting deposition number CCDC 1845554 for the Cobalt(III) complex (1).

\section{Acknowledgements}

The work is supported financially by the Department of Science and Technology (DST), New Delhi, India under FAST TRACK SCHEME for YOUNG SCIENTIST (NO. SB /FT/CS-088/2013 dtd. 21/05/2014). The single crystal Xray facility of the Department of Chemical Sciences, IISER Mohali is acknowledged for the data collection.

\section{References}

1. Reichmann M E, Rice S A, Thomas C A and Doty P 1954 A Further Examination of the Molecular Weight and Size of Desoxypentose Nucleic Acid J. Am. Chem. Soc. 763047

2. (a) Lahiri D, Majumdar R, Patra A K and Chakravarty A R 2010 Anaerobic DNA cleavage in red light by dicopper(II) complexes on disulphide bond activation J. Chem. Sci. 122 321; (b) Chowdhury B, Maji M and Biswas B 2017 Catalytic Aspects of a Copper(II) Complex: Biological Oxidase to Oxygenase Activity J. Chem. Sci. 129 1513; (c) De A, Dey D, Das D, Kole N and Biswas B 2018 J. Chem. Sci. 1301513

3. Dey D, De A, Pal S, Mitra P, Ranjani A, Gayathri L, Chandraleka S, Dhanasekaran D, Akbarsha M A, Kole N and Biswas B 2015 Synthesis, crystal structure, catecholase activity, DNA cleavage and anticancer activity of a dinuclear manganese(III)-bipyridine complex Indian. J. Chem. Sec. A $\mathbf{5 4} 170$

4. Trawick B N, Daniherl A T and Bashkin J K 1998 Inorganic Mimics of Ribonucleases and Ribozymes: From Random Cleavage to Sequence-Specific Chemistry to Catalytic Antisense Drugs Chem. Rev. 98939

5. (a) Protivinsky R 1971 Chemotherapeutics with tuberculostatic action Antibiot. Chemother. 17 101; (b) Joshi K C, Pathak V N and Jain S K 1980 Studies of potential organo-fluorine antibacterial agents. Part 5:
Synthesis and antibacterial activity of some new fluorinecontaining indole-2,3-dione derivatives Pharmazie $\mathbf{3 5}$ 677; (c) Biswas B, Patra M, Dutta S, Ganguly M and Kole N 2013 Synthesis, structural characterization and biological activity of a trinuclear zinc (II) complex: DNA interaction study and antimicrobial activity J. Chem. Sci. 125 1445; (d) Shepherd R G 1970 In Medicinal Chemistry A Burger (Ed.) (New York: Wiley)

6. (a) Sing S P, Shukla S K and Awasthi L P 1983 Synthesis of some 3-(4'-Benzoylhydrazono)-2-Indolinones As Potential Antiviral Agents Curr. Sci. 52 766; (b) Danda A, Kaur V and Singh P 1993 J. Ind. Pharm. Sci. 55129

7. McLain J, Lee J and Groves J T 2000 Biomimetic Oxidations Catalyzed by Transition Metal Complexes B Meunier (Ed.) (London: Imperial College Press)

8. Benedini F, Galliani G, Nali M, Rindone B and Tollari S 1985 Bis(salicylaldehyde)ethylenedi-iminecobalt(II)catalysed oxidation of aromatic amines with oxygen $J$. Chem. Soc., Perkin Trans. 21963

9. Simandi L I, Nemeth S and Rumlis N 1987 Cobalt(II) ion catalyzed oxidation of o-substituted anilines with molecular oxygen J. Mol. Catal. 42357

10. Szeverenyl Z, Mileava E R and Simandi L I 1991 Kinetics of the oxidation of 2-aminophenol by dioxygen in the presence of tetrakis(3,5-di-t-butyl-4-hydroxyphenyl)dodecachlorophthalocyaninatocobalt(II) J. Mol. Catal. 67251

11. Sakaue S, Tsubakino T, Nishiyama Y and Ishii Y 1993 Oxidation of aromatic amines with hydrogen peroxide catalyzed by cetylpyridinium heteropolyoxometalates $J$. Org. Chem. 583633

12. Kaizer J, Csonka R and Speier G 2002 TEMPO-initiated oxidation of 2-aminophenol to 2-aminophenoxazin-3one J. Mol. Catal. A: Chem. 18091

13. Horvath T, Kaizer J and Speier G 2004 Functional phenoxazinone synthase models: Kinetic studies on the copper-catalyzed oxygenation of 2-aminophenol J. Mol. Catal. A: Chem. 2159

14. Maurya M R, Sikarwar S, Joseph T and Halligudi S B 2005 Bis(2-[ $\alpha$-hydroxyethyl]benzimidazolato)copper (II) anchored onto chloromethylated polystyrene for the biomimetic oxidative coupling of 2-aminophenol to 2-aminophenoxazine-3-one J. Mol. Catal. A: Chem. 236132

15. Okamoto M S and Barefield E K 1974 Synthesis and stereochemistry of cobalt(III) complexes of 1,3diamino-2-propanol and related ligands Inorg. Chem. 13 2611

16. CrystalClear 2.0; Rigaku Corporation: Tokyo, Japan.

17. Sheldrick G M 2008 A short history of SHELX Acta. Cryst. A64 112

18. Dey S K and Mukherjee A 2015 Catechol oxidase and phenoxazinone synthase: Biomimetic functional models and mechanistic studies Coord. Chem. Rev. 31080

19. Simandi T M, Simandi L I, Gyor M, Rockenbauer A and Gomory A 2004 Kinetics and mechanism of the ferroxime(II)-catalysed biomimetic oxidation of 2aminophenol by dioxygen. A functional phenoxazinone synthase model Dalton Trans. 151056

20. Szigyarto I C, Simandi T M, Simandi L I, Korecz L and Nagy N 2006 A functional phenoxazinone synthase model based on dioximatomanganese(II): Kinetics and 
mechanism of the catalytic oxidation of 2-aminophenols by dioxygen, J. Mol. Catal. A: Chem. 251270

21. Bauer A W, Kirby W M M, Sherries J C and Truck M 1996 Antibiotic susceptibility testing by a standardized single disk method Am. J. Clin. Pathol. 45 493

22. Frisch M J, Trucks G W, Schlegel H B, Scuseria G E, Robb M A, Cheeseman J R, Scalmani G, Barone V, Mennucci B, Petersson G A, Nakatsuji H, Caricato M, Li X, Hratchian H P, Izmaylov A F, Bloino J, Zheng G, Sonnenberg J L, Hada M, Ehara M, Toyota K, Fukuda R, Hasegawa J, Ishida M, Nakajima T, Honda Y, Kitao O, Nakai H, Vreven T, Montgomery J A, Peralta J E Jr., Ogliaro F, Bearpark M, Heyd J J, Brothers E, Kudin K N, Staroverov V N, Kobayashi R, Normand J, Raghavachari K, Rendell A, Burant J C, Iyengar S S, Tomasi J, Cossi M, Rega N, Millam J M, Klene M, Knox J E, Cross J B, Bakken V, Adamo C, Jaramillo J, Gomperts R, Stratmann R E, Yazyev O, Austin A.J, Cammi R, Pomelli C, Ochterski J W, Martin R L, Morokuma K, Zakrzewski V G, Voth G A, Salvador P, Dannenberg J J, Dapprich $\mathrm{S}$, Daniels A D, Farkas O, Foresman J B, Ortiz J V, Cioslowski J, Fox D J, Gaussian 09 (Revision A.02), Gaussian, Inc., Wallingford, CT, 2009

23. Zhao Y and Truhlar D G 2006 A new local density functional for main-group thermochemistry, transition metal bonding, thermochemical kinetics, and noncovalent interactions J. Chem. Phys. 125194101

24. Paul S, Karar M, Mitra S, Shah S A S, Majumdar T and Mallick A 2016 A Molecular Lock with Hydrogen Sulfate as "Key" and Fluoride as "Hand": Computing Based Insights on the Functioning Mechanism ChemistrySelect 15547

25. Mennucci B, Cances E and Tomasi J 1997 Evaluation of Solvent Effects in Isotropic and Anisotropic Dielectrics and in Ionic Solutions with a Unified Integral Equation Method: Theoretical Bases, Computational Implementation, and Numerical Applications J. Phys. Chem. B 101 10506

26. Cances E, Mennucci E B and Tomasi J 1997 A new integral equation formalism for the polarizable continuum model: Theoretical background and applications to isotropic and anisotropic dielectrics J. Chem. Phys. 107 3032

27. Cammi R and Tomasi J 1995 Remarks on the use of the apparent surface charges (ASC) methods in solvation problems: Iterative versus matrix-inversion procedures and the renormalization of the apparent charges J. Comput. Chem. 161449

28. Miertus S, Scrocco E and Tomasi J 1981 Electrostatic interaction of a solute with a continuum. A direct utilizaion of $\mathrm{AB}$ initio molecular potentials for the prevision of solvent effects J. Chem. Phys. 55117

29. (a) Nakamoto K 2009 Infrared and Raman Spectra of Inorganic and Coordination Compounds, Part B: Applications in Coordination, Organometallic, and Bioinorganic Chemistry $6^{\text {th }}$ edn. (New Jersey: John Wiley \& Sons Inc.); (b) Dey D, Kaur G, Patra M, Choudhury A R, Kole N and Biswas B 2014 A perfectly linear trinuclear zinc-Schiff base complex: Synthesis, luminescence property and photocatalytic activity of zinc oxide nanoparticle Inorg. Chim. Acta 421335
30. (a) Dey D, Roy A B, Ranjani A, Gayathri L, Chandraleka S, Dhanasekaran D, Akbarsha M A, Shen C Y, Tsai H L, Majhi M, Kole N and Biswas B 2015 Synthesis and bio-catalytic activity of isostructural cobalt(III)phenanthroline complexes J. Chem. Sci. 127 649; (b) Das S, Ranjani A, Gayathri L, Saha S, Chandraleka S, Dhanasekaran D, Pasan J, Maji M, Akbarsha M A and Biswas B 2016 Recognition of self-assembled water-nitrate cluster in a $\mathrm{Co}$ (III)-2,2'-bipyridine host: Synthesis, crystal structure, DNA cleavage, molecular docking and anticancer activity $2016 \mathrm{~J}$. Chem. Sci. 128 1755; (c) Garai M, Dey D, Maji M, Yadav H R, Choudhury A R and Biswas B 2017 Synthesis and phosphatase activity of a cobalt(II)-phenanthroline complex J. Chem. Sci. 1291513

31. Bittner $\mathrm{M} M$, Lindeman $\mathrm{S} V$ and Fiedler $\mathrm{A} T$ 2012 A Synthetic Model of the Putative Fe(II)Iminobenzosemiquinonate Intermediate in the Catalytic Cycle of o-Aminophenol Dioxygenases J. Am. Chem. Soc. 1345460

32. Ely F, Hadler K S, Gahan L R, Guddat L W, Ollisand D L and Schenk G 2010 The organophosphate-degrading enzyme from Agrobacterium radiobacter displays mechanistic flexibility for catalysis J. Biochem. 432565

33. Mirams R E, Smith S J, Hadler K S, Ollis D L, Schenk $\mathrm{G}$ and Gahan L R 2008 Cadmium(II) complexes of the glycerophosphodiester-degrading enzyme GpdQ and a biomimetic N,O ligand J. Biol. Inorg. Chem. 131065

34. Lee M H and Dawson C R 1978 The specific activity value based on the prosthetic copper of ascorbate oxidase Arch. Biochem. Biophys. 191119

35. Malkin R, Malmstrom B G and Vanngard T 1969 Spectroscopic Differentiation of the Electron-Accepting Sites in Fungal Laccase Euro. J. Biochem. 10324

36. (a) Ramadan A M, Sala J M C and Parac-Vogt T N 2011 Trinuclear rare earth metal complexes based on 1,3,5triamino-1,3,5-trideoxy-cis inositol as catalysts for the hydrolysis of phosphodiesters Dalton Trans. 40 1230; (b) Phale P S, Basu A, Majhi P D, Deveryshetty J, Vamsee-Krishna C and Shrivastava R 2007 Metabolic Diversity in Bacterial Degradation of Aromatic Compounds OMICS: J. Integr. Biol. 11252

37. (a) Mukherjee C, Weyhermueller T, Bothe E, Rentschler E and Chaudhuri P 2007 A Tetracopper(II)-Tetraradical Cuboidal Core and Its Reactivity as a Functional Model of Phenoxazinone Synthase Inorg. Chem. 46 9895; (b) Barry C E III, Nayar P G and Begley T P 1989 Phenoxazinone synthase: mechanism for the formation of the phenoxazinone chromophore of actinomycin Biochemistry 28 6323; (c) Barry C E III, Nayar P G and Begley T P 1988 Phenoxazinone synthase: enzymatic catalysis of an aminophenol oxidative cascade J. Am. Chem. Soc. 110 3333; (d) Freeman J C, Nayar P G, Begley T P and J J Villafranca 1993 Stoichiometry and spectroscopic identity of copper centers in phenoxazinone synthase: a new addition to the blue copper oxidase family Biochemistry 324826

38. Mitra M and Ghosh R 2016 Phenoxazinone synthase activity of a mononuclear cobalt(III) complex Indian J. Chem. Sect. A 55681

39. Ghosh K, Harms K and Chattopadhyay S 2017 Two Cobalt(III) Schiff Base Complexes of the 
Type $[\mathrm{Co}(\mathrm{ABC})(\mathrm{DE}) \mathrm{X}]$ : Facile Synthesis, Characterization, Catechol Oxidase and Phenoxazinone Synthase Mimicking Activity ChemistrySelect 2 8207
40. Thimmaiah K N, Lloyd W D and Chandrappa G T 1985 Tereochemistry and Fungitoxicity of Complexes of P-Anisaldehydethiosemicarbazone with $\mathrm{Mn}$ (II), $\mathrm{Fe}(\mathrm{II})$, $\mathrm{Co}(\mathrm{II})$ and $\mathrm{Ni}$ (II) Inorg. Chim. Acta 16081 